\title{
Web-Based Interventions for Dietary Behavior in Adults With Type 2 Diabetes: Systematic Review of Randomized Controlled Trials
}

Jedha Dening, MNutr; Sheikh Mohammed Shariful Islam, PhD; Elena George, PhD; Ralph Maddison, PhD

Institute for Physical Activity and Nutrition, School of Exercise and Nutrition Sciences, Deakin University, Geelong, Victoria, Australia

Corresponding Author:

Sheikh Mohammed Shariful Islam, PhD

Institute for Physical Activity and Nutrition

School of Exercise and Nutrition Sciences

Deakin University

Locked Bag 20000

Geelong, Victoria, 3220

Australia

Phone: 61392468393

Email: shariful.islam@deakin.edu.au

\section{Abstract}

Background: Type 2 diabetes mellitus (T2DM) is among the most prevalent noncommunicable health conditions worldwide, affecting over 500 million people globally. Diet is a key aspect of T2DM management with dietary modification shown to elicit clinically meaningful outcomes such as improved glycemic control, and reductions in weight and cardiovascular disease risk factors. Web-based interventions provide a potentially convenient and accessible method for delivering dietary education, but its effects on dietary behavior in people with T2DM are unknown.

Objective: The objective of this review was to determine the effectiveness of web-based interventions on dietary behavior change and glycemic control in people with T2DM.

Methods: Per PRISMA (Preferred Reporting Items for Systematic Reviews and Meta-Analyses) guidelines, systematic literature searches were performed using Medline, Embase, The Cochrane Library, and CINAHL to retrieve papers from January 2013 to May 2019. Randomized controlled trials of web-based interventions in adults with T2DM with reported dietary assessment were included. Population and intervention characteristics, dietary guidelines and assessments, and significant clinical outcomes were extracted. Differences between groups and within groups were assessed for dietary behavior and clinical outcomes.

Results: There were 714 records screened, and five studies comprising 1056 adults were included. Studies measured dietary changes by assessing overall diet quality, changes in specific dietary components, or dietary knowledge scores. Significant improvements in dietary behavior were reported in four out of the five studies, representing healthier food choices, improvements in eating habits, reductions in carbohydrates, added sugar, sodium, saturated fat and overall fat intake, and/or increases in dietary knowledge. Three studies found significant mean reductions for hemoglobin A1c ranging from $-0.3 \%$ to $-0.8 \%$, and/or weight ranging from $-2.3 \mathrm{~kg}$ to $-12.7 \mathrm{~kg}$, fasting blood glucose $(-1 \mathrm{mmol} / \mathrm{L})$, waist circumference $(-1 \mathrm{~cm})$, and triglycerides $(-60.1$ $\mathrm{mg} / \mathrm{dL})$. These studies provided varied dietary recommendations from standard dietary guidelines, national health program guidelines, and a very low carbohydrate ketogenic diet.

Conclusions: This review provided evidence that web-based interventions may be an effective way to support dietary behavior change in people with T2DM, potentially leading to changes in glycemic control and other clinical outcomes. However, the evidence should be viewed as preliminary as there were only five studies included with considerable heterogeneity in terms of the diets recommended, the dietary assessment measures used, the complexity of the interventions, and the modes and methods of delivery.

(J Med Internet Res 2020;22(8):e16437) doi: 10.2196/16437

\section{KEYWORDS}

type 2 diabetes; dietary behavior; diet; glycemic control; self-management; eHealth; web-based; HbA1c 


\section{Introduction}

Type 2 diabetes mellitus (T2DM) is among the most prevalent noncommunicable diseases worldwide, estimated in 2018 to affect more than 500 million people across 45 countries [1]. T2DM is a metabolic disorder characterized by hyperglycemia; therefore, obtaining glycemic control is the overarching goal of T2DM treatment [2]. Glycemic control is generally defined as a hemoglobin $\mathrm{A}_{1 \mathrm{c}}\left(\mathrm{HbA}_{1 \mathrm{c}}\right)$ level of $7 \%$ or less. However, it is recognized that tighter glycemic control of $6.5 \%$ or less may further reduce the risk of macro and microvascular complications such as cardiovascular disease (CVD), neuropathy, nephropathy, and retinopathy [2], along with decreasing the risk of mortality [3]. The American Diabetes Association (ADA) [2] recommends education aimed at lifestyle modifications, including diet and physical activity, and prescription of medications as necessary for the management of T2DM.

It is well recognized that improving diet can optimize glycemic control, with research demonstrating improved diet quality can reduce $\mathrm{HbA}_{1 \mathrm{c}}$ to a similar or greater level than the provision of medication to patients with T2DM [2,4]. Even where medication is necessary, diet remains an important component of the overall treatment plan for people with T2DM [2]. Additionally, improved diet quality may optimize weight management, blood pressure, and lipid profile, which in turn may decrease the risk of CVD and stroke in people with T2DM [4]. Previous qualitative studies including people with T2DM, have confirmed that dietary support is one of their leading preferences for self-management education [5-8]. Nevertheless, there remains a substantial gap between the need for and the provision of dietary education for those with T2DM. Initial and ongoing diabetes education is the role of an individuals' multidisciplinary care team and/or provided by health care professionals or organizations through structured diabetes education programs [9]. However, rates of receiving any type of diabetes education are reported to be low globally, 23-66\% in the United States [10], $11 \%$ in the United Kingdom [11], and 40\% in Australia [9]. One explanation is access to and availability of health care professionals [6,12], the number of people with T2DM outweighing the number of health care professionals available to provide diabetes education [12]. Additionally, the cost and labor of delivering diabetes education programs face-to-face represent a significant challenge to organizations $[13,14]$.

For the past two decades, researchers have become increasingly interested in providing diabetes education via technological means, as it represents a delivery method that has greater reach and access for people with T2DM [15], and is potentially more cost-effective [16]. Compared to usual care, web-based programs in people with T2DM have been shown to reduce $\mathrm{HbA}_{1 \mathrm{c}}$ by $0.47 \%-1.49 \%$ [17], while mobile health (mHealth) interventions reduced $\mathrm{HbA}_{1 \mathrm{c}}$ by an average of $0.8 \%$ [18]. Interventions using mobile apps show reductions in $\mathrm{HbA}_{1 \mathrm{c}}$ of $0.4 \%-1.9 \%$ [19], and the provision of telehealth has been associated with an average $\mathrm{HbA}_{1 \mathrm{c}}$ reduction of $0.17 \%$ [20]. In terms of the influence of intervention features on $\mathrm{HbA}_{1 \mathrm{c}}$ outcomes in people with T2DM, when compared to mHealth and telehealth interventions, statistically significant results were only found for web-based interventions, which may indicate that web-based interventions are particularly useful for eliciting behavior change in people with T2DM [21].

Although people with T2DM need and want dietary education, web-based interventions to date have overwhelmingly focused on overall self-management [10,21,22]. While some interventions have included a healthy eating component within the intervention package, assessment of dietary adherence or behavior remains scarce. To date, we are not aware of any review that has investigated the effects of web-based interventions on change in dietary behavior in people with T2DM. Therefore, the primary aim of this systematic review was to identify and synthesize the available evidence from randomized controlled trials (RCTs) and determine the effectiveness of web-based interventions on dietary behavior change and glycemic control in people with T2DM.

\section{Methods}

This systematic review was conducted per the PRISMA (Preferred Reporting Items for Systematic Reviews and Meta-Analyses) guidelines [23]. The review protocol was registered at PROSPERO (International Prospective Register of Systematic Reviews) (2018 \#CRD42018109312).

\section{Eligibility Criteria}

Web-based interventions were included and defined as web-based if participants received information and directly interfaced with the internet, but they were not required to input data to a website [24]. In addition, studies were included if they were published in English; were RCTs or pilot RCTs; included an assessment of nutrition, diet, or dietary behavior; included adult participants ( $\geq 18$ years) with diagnosed T2DM. Exclusion criteria were studies using non-web-based digital interventions; studies including participants with prediabetes or type 1 diabetes; studies including a combination of T2DM and participants with other types of diabetes or where outcomes for multiple chronic diseases were assessed; and studies focused on diabetes prevention.

\section{Information Sources}

A systematic literature search of four electronic databases, Medline, Embase, The Cochrane Library, and CINAHL for relevant papers published between January 2013 and May 2019, was conducted. Papers published before January 2013 were excluded as previous systematic reviews have reported on web-based, computer-based, and digital interventions in people with T2DM up to this date $[22,25,26]$. From these reviews, we extracted papers that met our inclusion criteria. Additionally, we conducted an in-depth exploration of reference lists for related papers and searched grey literature, including Google Scholar.

\section{Search Strategy}

Keywords used in the search were ("Type 2 Diabet*" OR "diabetes mellitus, type 2" OR "T2DM" OR "T2D") AND ("web-based" OR "internet" OR "online" OR "digital" OR "information technology" OR "IT" OR "computer-assisted" 
OR “computer-based" OR “computer interface" OR "ehealth") AND ("diet*" OR "nutrition" OR "self-management" OR "lifestyle modification").

\section{Data Extraction}

Search results were merged using reference management software (Endnote 8) and duplicate papers removed. Screening of the titles and abstracts for individual studies were conducted in duplicate, independently, by two authors (JD, SI) with disagreements resolved by consensus. Articles deemed eligible for full-text review were assessed for eligibility by two authors, independently (JD, SI), and disagreements for inclusion were reached via consensus. Corresponding papers from the same study were merged to extract relevant outcomes. The following parameters were extracted from included studies: author/date, study design, sample size, total study period and length of follow up, population characteristics (including location, age, and comorbidities), behavioral change theory or model, digital intervention characteristics (including the type of digital intervention and duration of exposure), intervention providers, type of dietary intervention or guidelines administered, the dietary assessment used, dietary behavior change outcomes, and significant T2DM clinical outcomes including glycemic control as indicated by blood glucose levels or $\mathrm{HbA}_{1 \mathrm{c}}$, and biomarkers weight, waist circumference, and CVD biomarkers. We also extracted intervention components, website usability rates, modes and methods of delivery, and process evaluation measures.

\section{Assessment of Study Risk of Bias}

The risk of bias was assessed by two researchers independently using the Cochrane risk-of-bias tool for randomized trials (RoB
2) [27]. RoB 2 provides an in-depth framework structured into five domains to assess the risk of bias in RCTs. These five domains assess the risk of bias arising from the randomization process, deviations from intended interventions, missing outcome data, outcome measurements, and selection of reported results. During the assessment, each domain is given a rating of low, high, or unclear. Conflicting assessment ratings were resolved by consensus. Results were then calculated to reach a quality assessment rating of poor, fair, or good quality.

\section{Data Analysis}

For qualitative analysis, differences in end intervention measures between groups and change between groups were reported, depending on the outcomes reported for individual studies. We also reported significant within-group changes. Data were considered statistically significant if the reported $P$ value was $<.05$.

\section{Results}

The search identified a total of 714 papers, of which 15 full-text articles were assessed for eligibility, and five studies met the inclusion criteria and were included in this review (Figure 1) [28-32]. Corresponding papers from the same studies [33-37] provided supporting information extracted for this review. Four of the studies reviewed were RCTs, and one was a pilot RCT. Each study described a web-based intervention where participants received information that directly interfaced with the internet and included some form of dietary assessment. All the studies included only adults with T2DM; a summary of the included studies is shown in Table 1.

Figure 1. Prisma Flow Chart.

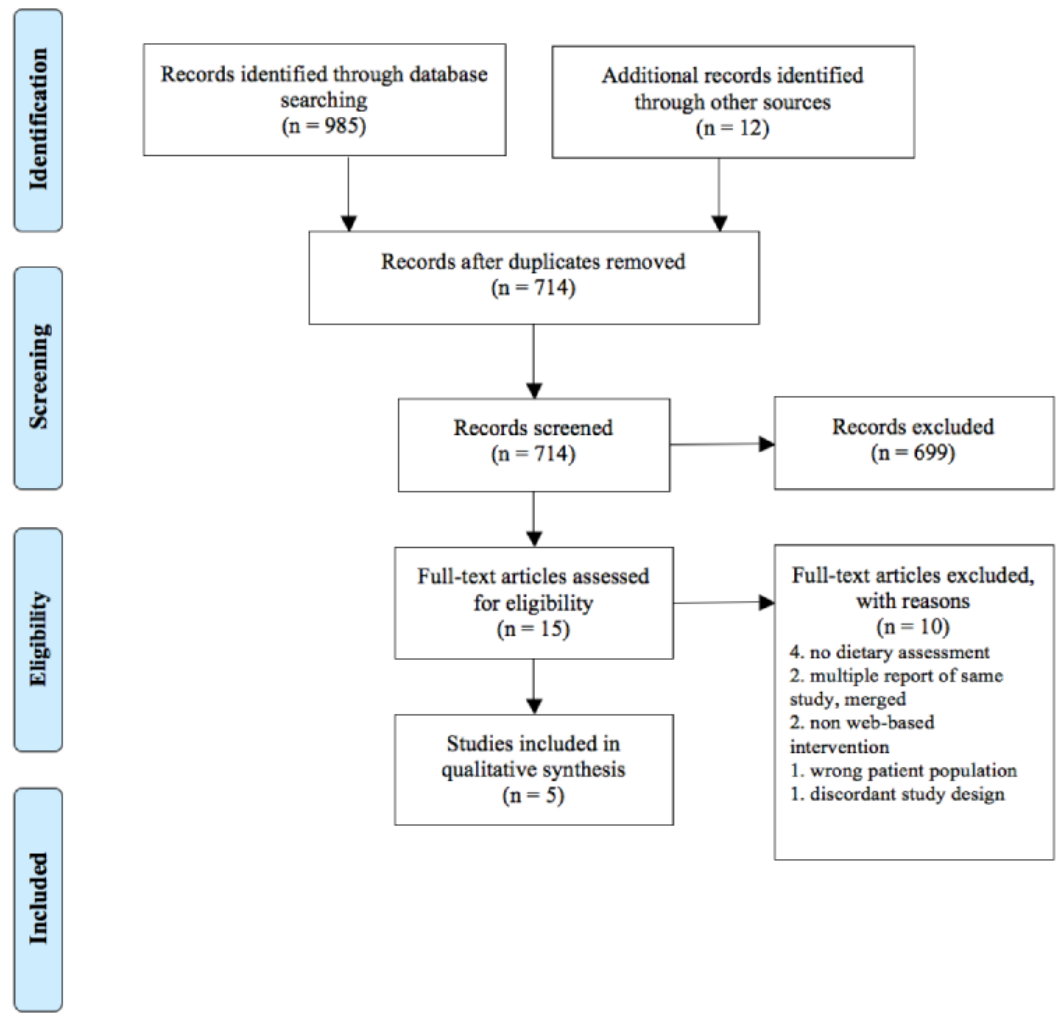


Table 1. Summary of study characteristics for included randomized controlled trials.

\begin{tabular}{|c|c|c|c|c|c|c|c|}
\hline Author/date & $\begin{array}{l}\text { Study de- } \\
\text { sign }\end{array}$ & $\begin{array}{l}\text { Sample } \\
\text { size, } \mathrm{N}\end{array}$ & $\begin{array}{l}\text { Population charac- } \\
\text { teristics }\end{array}$ & Theory/model & $\begin{array}{l}\text { Intervention partici- } \\
\text { pants, N, program } \\
\text { name, digital interven- } \\
\text { tion characteristics }\end{array}$ & $\begin{array}{l}\text { Type of diets pre- } \\
\text { scribed }\end{array}$ & $\begin{array}{l}\text { Intervention/follow- } \\
\text { up period }\end{array}$ \\
\hline $\begin{array}{l}\text { Ramadas et } \\
\text { al, } 2018 \text { [29] }\end{array}$ & $\mathrm{RCT}^{\mathrm{a}}$ & 128 & $\begin{array}{l}\text { Adults with } \\
\text { T2DM }{ }^{\text {b }} \text {, mean } \\
\text { age } 50.5 \text { years, } \\
\text { most with a fami- } \\
\text { ly history of } \\
\text { T2DM. Malaysia }\end{array}$ & $\begin{array}{l}\text { Transtheoretical } \\
\text { Model Stages of } \\
\text { Change, user- } \\
\text { centered design }\end{array}$ & $\begin{array}{l}\mathrm{N}=62, \text { myDIDeA }^{\mathrm{c}}, \text { re- } \\
\text { ceived personalized in- } \\
\text { tensive dietary interven- } \\
\text { tion via website }+ \text { stan- } \\
\text { dard care }\end{array}$ & $\begin{array}{l}\mathrm{IG}^{\mathrm{d}} \text { : standard dietary } \\
\text { guidelines } \\
\mathrm{CG}^{\mathrm{e}} \text { : no prescribed } \\
\text { diet }\end{array}$ & $\begin{array}{l}\text { 6-month intervention, } \\
\text { 12-month follow-up }\end{array}$ \\
\hline $\begin{array}{l}\text { Hansel et al, } \\
2017 \text { [28] }\end{array}$ & RCT & 120 & $\begin{array}{l}\text { Adults with ab- } \\
\text { dominal obesity } \\
\text { and T2DM, mean } \\
\text { age } 57 \text { years. } \\
\text { Paris }\end{array}$ & $\begin{array}{l}\text { No theory report- } \\
\text { ed }\end{array}$ & $\begin{array}{l}\mathrm{N}=60, \mathrm{ANODE}^{\mathrm{f}} \text {, fully } \\
\text { automated web-based } \\
\text { nutritional support pro- } \\
\text { gram }\end{array}$ & $\begin{array}{l}\text { IG: National Nutri- } \\
\text { tion \& Health Pro- } \\
\text { gram guidelines } \\
\text { CG: received gener- } \\
\text { al diet advice }\end{array}$ & 16-week intervention \\
\hline $\begin{array}{l}\text { Saslow et al, } \\
2017 \text { [30] }\end{array}$ & $\begin{array}{l}\text { Pilot } \\
\text { RCT }\end{array}$ & 25 & $\begin{array}{l}\text { Overweight } \\
\text { adults with } \\
\text { T2DM, mean age } \\
55.6 \text { years. Cali- } \\
\text { fornia }\end{array}$ & $\begin{array}{l}\text { No theory report- } \\
\text { ed }\end{array}$ & $\begin{array}{l}\mathrm{N}=12 \text {, dietary instruc- } \\
\text { tion provided via email } \\
\text { lessons including mind- } \\
\text { fulness training and } \\
\text { lifestyle advice }\end{array}$ & $\begin{array}{l}\text { IG: VLKCD }{ }^{\mathrm{g}}(20-50 \\
\text { g/carbs per day }) \\
\text { CG: ADA " "create } \\
\text { your plate" diet }\end{array}$ & $\begin{array}{l}\text { 16-week intervention, } \\
\text { 32-week follow-up }\end{array}$ \\
\hline $\begin{array}{l}\text { Glasgow et } \\
\text { al, } 2003 \text { [31] }\end{array}$ & $\mathrm{RCT}$ & 320 & $\begin{array}{l}\text { Adults with } \\
\text { T2DM, mean age } \\
59 \text { years. Col- } \\
\text { orado }\end{array}$ & $\begin{array}{l}\text { Self-efficacy the- } \\
\text { ory, social sup- } \\
\text { port theory }\end{array}$ & $\begin{array}{l}\mathrm{N}=\mathrm{N} / \mathrm{A}^{\mathrm{i}}, \mathrm{D}-\mathrm{Net}^{\mathrm{j}}, \text { two } \\
\text { intervention arms: tai- } \\
\text { lored self-management } \\
\text { training, peer support }\end{array}$ & $\begin{array}{l}\text { All groups received } \\
\text { general healthy eat- } \\
\text { ing advice to de- } \\
\text { crease fat and in- } \\
\text { crease fruit and veg- } \\
\text { etable intake }\end{array}$ & $\begin{array}{l}\text { 3-month intervention, } \\
10 \text {-month follow-up }\end{array}$ \\
\hline $\begin{array}{l}\text { Glasgow et } \\
\text { al, } 2012 \text { [32] }\end{array}$ & $\mathrm{RCT}$ & 463 & $\begin{array}{l}\text { Adults with } \\
\text { T2DM, mean age } \\
58.4 \text { years. Col- } \\
\text { orado }\end{array}$ & $\begin{array}{l}\text { Social-ecological } \\
\text { theory, social } \\
\text { cognitive theory } \\
\text { and the "5 As" } \\
\text { self-management } \\
\text { model }\end{array}$ & $\begin{array}{l}\mathrm{N}=189 \text {, two interven- } \\
\text { tion arms: } \mathrm{CASM}^{\mathrm{k}} \text { : } \\
\text { self-administered com- } \\
\text { puter-assisted self-man- } \\
\text { agement; } \mathrm{N}=182 \text {, } \\
\mathrm{CASM}+{ }^{1} \text { with enhanced } \\
\text { social support }\end{array}$ & $\begin{array}{l}\text { All groups received } \\
\text { general advice to de- } \\
\text { crease fat and eat a } \\
\text { healthy diet }\end{array}$ & $\begin{array}{l}\text { 4-month intervention, } \\
\text { 12-month follow-up }\end{array}$ \\
\hline
\end{tabular}

${ }^{\mathrm{a}} \mathrm{RCT}$ : randomized controlled trial.

${ }^{\mathrm{b}}$ T2DM: type 2 diabetes mellitus.

${ }^{c}$ myDIDeA: Malaysian Dietary Intervention for People with Type 2 Diabetes: An e-Approach.

${ }^{\mathrm{d}} \mathrm{IG}$ : intervention group.

${ }^{\mathrm{e}} \mathrm{CG}$ : control group.

${ }^{\mathrm{f}}$ ANODE: Accompagnement Nutritionnel de l'Obésité et du Diabète par Ecoaching.

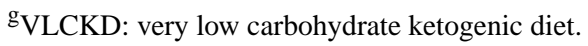

${ }^{\mathrm{h}} \mathrm{ADA}$ : American Diabetes Association.

${ }^{\mathrm{i}} \mathrm{N} / \mathrm{A}$ : not applicable.

${ }^{\mathrm{j}}$ D-Net: Diabetes Network.

${ }^{\mathrm{k}} \mathrm{CASM}$ : computer-assisted self-management.

${ }^{1} \mathrm{CASM}+$ : computer-assisted self-management plus social support.

\section{Participants and Intervention Characteristics}

The included studies provided results from a total of 1056 participants representing three countries-France [28], Malaysia [29], and the United States [30-32]. The number of participants ranged from $\leq 26$ in the pilot study [30] to $\leq 463$ in the RCTs [32]. The mean age of participants ranged from 50.5 years [29] to 59 years [32]. Three studies had an intervention period of 4 months [28,30,32], one was 3 months [31], and one was 6 months [29]. Two studies included a 12-month follow up [29,32], one had a 10-month follow up [31], and another had a 32-week follow up [30]. The Malaysian Dietary Intervention for People with Type 2 Diabetes: An e-Approach (myDIDeA) [29] focused solely on dietary behavior by providing participants with a personalized intensive dietary intervention. The remaining studies assessed dietary behavior but included dietary recommendations alongside physical activity [28,30], mindfulness training [30], social support and self-management information [31,32], and face-to-face contact [32]. Three studies included health practitioner-assistance [29,31,32], ranging from contact with a nutritionist $[29,32]$ through to availability of health care coaches and professionals [31,32], and physicians [32]. The Accompagnement Nutritionnel de l'Obésité et du Diabète par Ecoaching (ANODE) study [28] was a fully 
automated intervention aside from providing technical assistance. Three studies [29,31,32] utilized behavioral theories or models, which varied widely. Only myDIDeA [29] applied user-centered design theory to support intervention development.

\section{Dietary Recommendations and Measurement}

Three of the studies indicated the type of dietary recommendations prescribed [28-30], which were standard diabetes dietary guidelines modified to suit the Malaysian population [29], the National Nutrition and Health Program guidelines of France [28], and a very low carbohydrate ketogenic diet (VLCKD) [30]. The remaining two studies, computer-assisted self-management/computer-assisted self-management plus social support (CASM/+) [32] and the Diabetes Network (D-Net) [31], provided self-administered and/or personalized tailored dietary instruction from health professionals with general healthy eating recommendations and goal setting to reduce fast foods, fried foods, or sugar-sweetened beverages, and increase fruit and vegetable consumption. The tools and scales used for dietary assessment varied widely across all five studies (Table 2). myDIDeA [29] used a validated Malaysian 36-item Dietary Knowledge, Attitude, and Behavior (DKAB) score. ANODE [28] used the International Diet Quality Index (DQI-I) with food frequency questionnaires from both 24-hour and 3-day diet recalls. CASM/+ [32] used dietary questionnaires measured by two validated scales, the 20-item Kristal Fat and Fiber Behavior scale (FFB) and the 15-item Block/National Cancer Institute (NCI) Fat Screener. D-Net [31] also used the Block/NCI Fat Screener along with the 8-item "Starting the Conversation" scale. The VLCKD [30] used unvalidated self-reported dietary intake obtained from participants' entries on a consumer-based website. 
Table 2. An overview of dietary behavioral outcomes.

\begin{tabular}{|c|c|c|c|}
\hline Reference & Dietary assessment & Baseline dietary assessment results & Postintervention dietary changes \\
\hline Ramadas et al, 2018 [29] & DKAB $^{\mathrm{a}}$ score, DSOC $^{\mathrm{b}}$ & $\begin{array}{l}\mathrm{IG}^{\mathrm{c}}: \text { DKAB } 34.2(5.2), \text { DSOC } 193.3(14.6) \\
\mathrm{CG}^{\mathrm{d}}: \text { DKAB } 33.7(5.5), \text { DSOC } 191.2 \\
(16.2)\end{array}$ & $\begin{array}{l}\text { IG: DKAB } 54.0 \text { (8.7), DSOC } 199.7(18.2) \\
\text { CG:DKAB } 41.3 \text { (7.7), DSOC } 191.5(15.1) \\
\text { DKAB score significantly improved in both } \\
\text { groups with the margin of improvement higher } \\
\text { in the IG, a difference of } 12.2 \text { points between } \\
\text { groups. No difference between groups in DSOC } \\
\text { at } 6 \text { months. IG showed improved DCOS at 12- } \\
\text { month follow-up and no change in CG }\end{array}$ \\
\hline
\end{tabular}

$\begin{array}{lll}\text { Hansel et al, } 2017 \text { [28] } & \text { DQI-I } & \text { IG: DQI-I } 54.0 \\ & & \text { CG: DQI-I } 52.8\end{array}$

Saslow et al, 2017 [30]

Self-reported dietary intake (MyFitnessPal) and self-reported subjective experience of diets

Glasgow et al, 2003 [31]

Glasgow et al, 2012 [32]

$\mathrm{FFB}^{\mathrm{f}}$ and the $\mathrm{NCI}^{\mathrm{g}}$ Fat Screener

"Starting the Conversation" scale and NCI Fat Screener
CG: DQI-I 52.8

IG: nonfiber carbohydrates (g) 163.6 (86.7), fat (g) 77.1 (41.4), protein (g) 83.3 (18.0), sugar (g) 50.6 (33.8)

CG: nonfiber carbohydrates (g) 152.0 (58.9), fat (g) 81.3 (27.3), protein (g) 74.5 (17.2), sugar (g) 44.9 (23.8)

Not reported

IG: eating habits $2.18(0.2)$, fat intake $34.86(28)$

CG: eating habits $2.13(0.3)$, fat intake $35.18(40)$
IG: Significant increase in the DQI-I score of 4.55 , total 58.55

CG: Decrease in DQI-I score of -1.68 , total 51.12

Dietary changes towards healthier foods were noted in the IG, particularly for saturated fat $(P=.02)$ and sodium $(P<.001)$

Self-reported dietary intake showed the IG ate fewer grams of nonfiber carbohydrates and sugar compared to CG. No differences in protein and fat between groups. Change in mean carbohydrate intake in IG from $39.6 \%$ of calories to $15.5 \%$. Compared to CG, IG rated themselves as less likely to cheat on their diet, with a large effect size of at least Cohen $d=-1.0$

Trending improvements in FFB in both IGs but no significant differences between groups

IG: eating habits 2.32 (0.2), fat intake 33.22 (24) CG: eating habits $2.23(0.3)$, fat intake 33.91 (37)

The combined IG CASM ${ }^{\mathrm{h}} / \mathrm{CASM}+{ }^{\mathrm{i}}$ significantly improved eating habits more than CG over 12 months (chi-square $=9.01)$, fat intake (chisquare $=6.01$ )

${ }^{a}$ DKAB: Dietary Knowledge, Attitude, and Behavior.

${ }^{b}$ DSOC: Dietary Stages of Change.

${ }^{\mathrm{c}} \mathrm{IG}$ : intervention group.

${ }^{\mathrm{d}} \mathrm{CG}$ : control group.

${ }^{\mathrm{e}}$ DQI-I: International Diet Quality Index.

${ }^{f}$ FFB: Kristal Fat and Fiber Behavior scale.

${ }^{\mathrm{g}}$ NCI: National Cancer Institute.

${ }^{\mathrm{h}} \mathrm{CASM}$ : computer-assisted self-management.

${ }^{i}$ CASM+: computer-assisted self-management plus social support.

\section{Dietary Behavior Change and Clinical Outcomes}

Four of the studies reported a statistically significant dietary behavior change in the intervention group (Table 2) [28-30,32]. Compared to a control group receiving usual care, ANODE [28] found significant improvements in dietary quality with participants choosing healthier foods overall and improvements in saturated fat and sodium intake. Similarly, compared to an enhanced care control group, CASM/+ [32] found that participants' overall eating habits improved along with reductions in overall fat intake. Compared to a control group prescribed the ADA's "create-your-plate" diet, participants following a VLCKD [30] demonstrated adherence with decreased consumption of carbohydrates within the prescribed range of 20-50 grams per day and decreased consumption of added sugar. Compared to a control group prescribed usual care, myDIDeA [29] showed that web-based interventions could be a feasible option for supporting dietary behavior change for people with T2DM in developing countries such as Malaysia, with participants in the intervention group achieving a 12.2-point difference in DKAB score. CASM/+ [32] demonstrated dietary behavior change in individuals with lower literacy and numeracy and diverse and higher-risk populations such as American Indian/Alaska Native, Asian, Black and African American, and Latino.

Changes in clinical outcomes were inconsistent and differed across studies (Table 3). Two studies reported statistically 
significant improvements in glycemic control for $\mathrm{HbA}_{1 \mathrm{c}}$ between groups compared to usual care [28] and the ADA's "create-your-plate" diet [30]. One study found significant between-group differences in fasting blood glucose and $\mathrm{HbA}_{1 \mathrm{c}}$ [29] compared to usual care, benefits that were only observed in the intervention group at 12-months follow-up. However, clinical outcomes were not reflected across all four studies that reported significant changes in dietary behavior. CASM/+ [32] reported no significant clinical improvements. Reductions in weight or waist circumference were seen in two studies $[28,30]$.
Twenty percent of the ANODE study's [28] intervention participants achieved $>5 \%$ weight loss, and $90 \%$ achieved at least $5 \%$ weight loss in the VLCKD intervention [30]. Weight reductions could be explained by improved overall diet quality and decreased fat intake [28], decreased sugar and carbohydrate consumption [30], greater calorie deficits in both intervention groups compared to control groups, along with recommendations for physical activity included in both interventions. Additionally, following a VLCKD yielded significant reductions in triglycerides [30].

Table 3. Significant clinical outcomes for dietary intervention groups. Data were considered statistically significant if $P<.05$.

\begin{tabular}{|c|c|c|c|c|c|}
\hline $\begin{array}{l}\text { Author/date/reported mean } \\
\text { and outcomes measured }\end{array}$ & Baseline & Timepoint & Outcome & $\begin{array}{l}\text { Within-group } \\
\text { changes ( } P \text { value })\end{array}$ & $\begin{array}{l}\text { Between-group } \\
\text { changes ( } P \text { value })\end{array}$ \\
\hline \multicolumn{6}{|l|}{ Ramadas et al, 2018 [29], mean (SD) } \\
\hline $\mathrm{HbA}_{1 \mathrm{c}}^{\mathrm{a}}(\%)$ & $9.1(2.0)$ & $\begin{array}{l}6 \text { months }=8.7 \\
(1.9)\end{array}$ & $\begin{array}{l}12 \text { months }=8.5 \\
(1.8)\end{array}$ & .004 & $-^{b}$ \\
\hline Fasting blood glucose $(\mathrm{mmol} / \mathrm{L})$ & $8.9(3.9)$ & $\begin{array}{l}6 \text { months }=8.1 \\
(2.7)\end{array}$ & $\begin{array}{l}12 \text { months }=7.9 \\
(2.5)\end{array}$ & .015 & - \\
\hline \multicolumn{6}{|l|}{ Hansel et al, 2017 [28], mean (SD) } \\
\hline $\mathrm{HbA}_{1 \mathrm{c}}(\%)$ & $7.16(0.78)$ & - & $6.86(0.94)$ & - & $<.001$ \\
\hline Weight $(\mathrm{kg})$ & $93.3(16.2)$ & - & $91(3.0)$ & - & .01 \\
\hline Waist circumference $(\mathrm{cm})$ & $110(10)$ & - & $109.1(4.7)$ & - & .01 \\
\hline \multicolumn{6}{|c|}{ Saslow et al, 2017 [30], mean (SD) and mean $\left(\mathrm{EMM}^{\mathrm{c}}\right)$} \\
\hline $\mathrm{HbA}_{1 \mathrm{c}}(\%)$ & $7.1(0.4)$ & $\begin{array}{l}16 \text { weeks }=6.2 \\
(-1.1,-0.6)\end{array}$ & $\begin{array}{l}32 \text { weeks }=6.3 \\
(-1.1,-0.6)\end{array}$ & - & .002 \\
\hline Weight (kg) & $109(24.9)$ & $\begin{array}{l}16 \text { weeks }=100.5 \\
(-11.9,-5.2)\end{array}$ & $\begin{array}{l}32 \text { weeks }=96.3 \\
(-7.3,1.3)\end{array}$ & - & $<.001$ \\
\hline Triglycerides (mg/dL) & $183(135)$ & $\begin{array}{l}16 \text { weeks }=147.5 \\
(-65.7,-5.2 \mathrm{EMM})\end{array}$ & $\begin{array}{l}32 \text { weeks }=122.9 \\
(-46.0,33.6 \\
\text { EMM })\end{array}$ & - & .01 \\
\hline
\end{tabular}

${ }^{\mathrm{a}} \mathrm{HbA}_{1 \mathrm{c}}$ : hemoglobin $\mathrm{A}_{1 \mathrm{c}}$

${ }^{\mathrm{b}}$ Not applicable

${ }^{c}$ EMM: estimated marginal means.

\section{Attrition, Website Features, and Usability}

An overview of intervention components, attrition, usability, and modes and methods used to deliver the interventions is shown in Multimedia Appendix 1. The attrition rate varied among studies, with the highest dropout rate seen in the CASM/+ interventions [32], losing 34.2\% of intervention participants randomized to two complex intervention arms, compared to $19.5 \%$ of the control group. The lowest attrition rate was seen in myDIDeA, losing $4.8 \%$ of intervention participants and $10.6 \%$ of the control group, perhaps because the intervention focused solely on providing a structured dietary intervention and implemented a user-centered approach. Across all web-based interventions, the highest website usage was reported in the first month, followed by declined usage over time. Three studies reported login rates as a measure for usability [28,31,32]. Only one study [29] reported both login rates and time spent on site. Various modes and methods of delivering intervention components were reported, including providing content on a website, which was used in four of the five studies $[28,29,31,32]$, while one sent content via email with text, videos, and links to various web resources [30]. Four studies provided some form of self-monitoring and feedback, whether automated or assisted by a health care professional [28,29,31,32]. Three of the five interventions [29-31] provided updated intervention materials to participants ranging from biweekly to bimonthly. No associations could be drawn between these methods and participant adherence and intervention outcomes due to heterogeneity in the methods of delivery and a lack of detailed reporting.

\section{Postintervention Process Evaluation}

Postintervention process evaluation measured levels of adherence, usability, acceptability, and program satisfaction (Multimedia Appendix 2). The most common statistic used to measure adherence or intervention usage was website login rates [28,29,31,32], with studies consistently demonstrating higher login rates early in the intervention (Multimedia 
Appendix 1). Two studies included a more comprehensive process evaluation [28,29], both of which provided participants with self-reported feedback questionnaires. myDIDeA [29] usability rates were $72 \%$, acceptability $62 \%$, and program satisfaction $64 \%$. ANODE's [28] satisfaction rate was $70 \%$. D-Net [31] indicated an implementation percentage of $100 \%$ related to their dietary assessment component but did not provide overall satisfaction rates.

\section{Overall Study Quality}

Figure 2 summarizes the risk-of-bias assessment [27]. Four studies had a reasonable sequence generation described [28,30-32]. It was unclear in three studies if allocation concealment was adequate [29,30,32]. Only one study sufficiently blinded participants and personnel [29], one study was unclear [31], while the remainder did not blind [28,30,32]. However, blinding in dietary behavior studies is often not feasible. Three studies sufficiently blinded outcome assessors [28-30], while two remained unclear [31,32]. Only one study failed to provide complete outcome data [30]. Two studies reported full datasets [28,31], two were unclear [30,32], while one [29] had several outcomes included in study protocols [36] that were missing from the final study outcomes. Other biases were low [28,31,32] or unclear [29,30]. Based on these assessments, only one study [28] was assessed to be of fair quality, while the remaining four were assessed to be of poor quality.

Figure 2. Risk of bias. Judgments about each risk of bias item presented as percentages across all included studies.

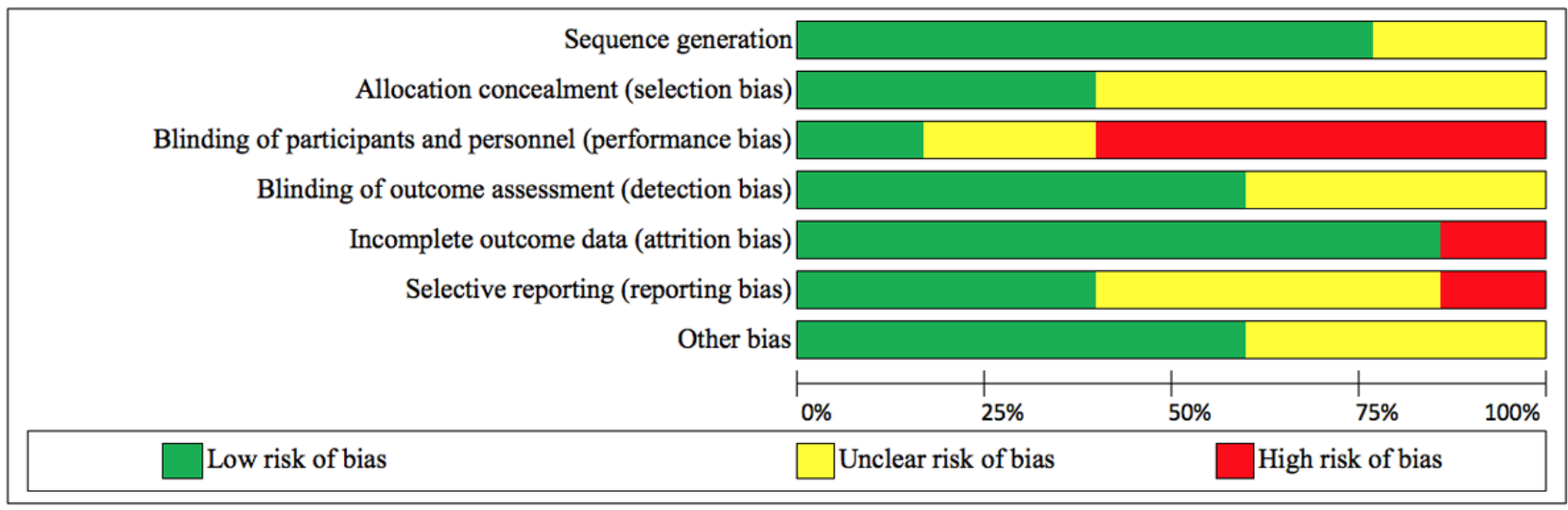

\section{Discussion}

This systematic review is the first to demonstrate the potential for web-based interventions to achieve significant improvements in dietary behavior in people with T2DM. Moreover, this review showed that improved glycemic control could be achieved using web-based dietary interventions. However, improvements in dietary behavior did not consistently result in improvements in glycemic control across studies.

One explanation for this inconsistency may be the varied dietary recommendations provided to participants across the studies (Table 1). While it is recognized that various dietary patterns are suitable for the management of T2DM [2], it appears that providing participants with more direct dietary recommendations may facilitate greater clinical outcomes. The ANODE study prescribed the National Nutrition and Health Program guidelines of France, myDIDeA prescribed evidence-based standard diabetes dietary guidelines modified to suit the Malaysian population, and the VLCKD prescribed specific guidelines for carbohydrate consumption. In contrast, CASM/+ only provided participants with general healthy eating information. Another explanation may be intervention complexity, as web-based dietary interventions in this review varied widely in terms of the number of components provided to participants (Multimedia Appendix 1). Previous literature [6,38] indicated overly complex interventions might provoke a lack of motivation due to confusion, provision of irrelevant content, and technical difficulties.
Regardless of the setting, patient engagement and adherence to their recommended care plan is an important issue [39]. Our review confirms previous observations [22,25] that usage of web and computer-based interventions decreases over time, with the highest usage seen in the first month. This pattern is particularly concerning as the studies in this review had intervention periods of only 3-6 months, highlighting the challenge of engaging participants in a web-based environment even over the short term. The majority of studies in this review reported only login rates as a measure for usability [28,31,32]. Login rates capture only a broad measure of website usage, providing little information about engagement with an intervention [15]. Only one study [29] provided evidence of engagement, reporting both login rates and time spent on the site, with a consistent level of engagement observed across the 6-month intervention for all participants. This consistency may have been due to the provision of structured dietary education modules. In face-to-face settings, structured education has been demonstrated to be effective for assisting people with T2DM to improve glycemic control and overall health [2]. Various authors suggest social support may increase participation $[10,21]$; however, this was not demonstrated in our results, as even the more complex web-based interventions offering contact with peers [31,32], and/or health care professionals [29,31,32] contributed no difference in terms of achieving clinical outcomes.

myDIDeA [29] was the first study to focus solely on providing a web-based dietary behavior change intervention for people with T2DM in Malaysia, providing the longest intervention 
period of 6-months with a 12-month follow-up. The intervention group showed a 12.2-point greater DKAB score compared to the control group (Table 2). While no between-group changes were found for clinical outcomes (Table 3), within-group changes in fasting blood glucose and $\mathrm{HbA}_{1 \mathrm{c}}$ were only found in the intervention group at 12-months follow-up, which may indicate that web-based dietary interventions could continue to influence behavior change beyond the intervention period. Furthermore, myDIDeA had the lowest overall attrition rate, which may be explained by the provision of an intervention solely focused on diet. Since determining what to eat is a significant challenge for people with T2DM [2], this specific dietary focus and the structured nature of delivering the components may have encouraged clarity, fostering longer-term commitment. Additionally, myDIDeA integrated a user-centered approach during the development of the intervention. User-centered design is a human-factor engineering strategy for designing user-friendly platforms [40], a method that has been described in other web-based T2DM self-management interventions $[41,42]$.

The Medical Research Council [39] suggests that best practice for complex interventions is using the best available evidence and appropriate theory. According to a systematic review and meta-analysis [43] of diet behavior change techniques in people with T2DM, the only intervention feature associated with significant reductions in $\mathrm{HbA}_{1 \mathrm{c}}$ was the application of a theoretical model or framework. However, the relationship between theoretical application and clinical outcomes has yet to be confirmed in web-based dietary behavior change interventions. For instance, the ANODE study [28] demonstrated statistically significant improvements in both dietary behavior and clinical outcomes, yet there was no theoretical basis for the development of the program. Rather it was a nutritional support tool developed by a private company.

Changes in glycemic control ranged from $\mathrm{HbA}_{1 \mathrm{c}}$ reductions of $0.3 \%$ [28] to $0.8 \%$ [30]. These results are clinically meaningful as previous research has demonstrated that for every $1 \%$ reduction in $\mathrm{HbA}_{1 \mathrm{c}}$, there is an associated risk reduction for heart attacks, microvascular complications, and deaths related to diabetes [3]. Achieving modest weight loss of $\geq 5 \%$ has been shown to improve glycemic control [2], a goal that was achieved by participants in the two studies that found statistically significant clinical outcomes between groups [28,30]. The VLCKD [30] produced the most significant results overall, with reductions in $\mathrm{HbA}_{1 \mathrm{c}}$, weight, and triglycerides. However, these results should be interpreted with caution due to the small study size. Furthermore, systematic reviews and meta-analysis of RCTs prescribing low-carbohydrate diets in people with T2DM [44], suggest that adherence to VLCKD interventions $(<50$ grams carbohydrates per day) are frequently poor and more difficult for people to maintain than a low-carbohydrate diet (50-130 grams carbohydrates per day), with no additional clinical benefits over a prescribed low-carbohydrate diet [45]. Overall, the results of this review demonstrated that, regardless of diet characteristics, participants who adhered to dietary recommendations showed improvements in their food choices and overall dietary quality, which improved clinical outcomes in most cases.

\section{Limitations and Future Research}

Only five studies met the eligibility criteria, and these were heterogeneous in terms of dietary recommendations, focus on diet alone or with additional behavioral components, behavioral theories and models applied, and target population. The modes and methods of delivering the web-based interventions also differed, and the duration and follow up periods varied widely. While most studies report statistically significant improvements in dietary behavior change, the use of different dietary assessment measures made it difficult to compare study outcomes and generalize results. Web-based interventions could improve and expand reporting of website statistics to help inform patterns of participant behavior, and consideration of measuring adherence to diet as a means of determining if greater adherence leads to greater improvement in clinical outcomes is warranted. Web-based interventions could be a cost-effective way to provide education and support to individuals with T2DM, broadening access for a greater number of people, including those who have location or mobility constraints and cannot access face-to-face services. More research is needed to explore web-based dietary interventions for these diverse populations, including younger adults and the elderly. Web-based dietary interventions must be studied in larger cohorts, for longer durations, and with more clearly defined dietary recommendations. Studies must also explore intervention content, modes and methods of delivery, and whether these enhance participant engagement or contribute meaningfully to the expected outcomes.

\section{Conclusion}

This review provided evidence that web-based interventions may be an effective way to improve dietary behavior in people with T2DM. The results also suggest improvements in glycemic control and clinical outcomes may be possible, although the studies in this review yielded inconsistent results. While this preliminary evidence showed promise of a positive effect, the small number of studies and the fact they are highly heterogeneous makes it difficult to draw any firm conclusions. The field requires more well-designed web-based dietary interventions that report dietary prescription and adherence in people with T2DM to confirm their effectiveness in optimizing dietary behavior and improving clinical outcomes.

\section{Acknowledgments}

SI designed and registered this review and supervised study procedures. JD conducted data extraction and analyses under the supervision of SI. JD wrote the manuscript with critical input from SI, EG, and RM. We would like to thank Reza Daryabeygi-Khotbehsara for research assistance with the risk-of-bias assessment. 


\section{Conflicts of Interest}

JD is a co-owner of Diabetes Meal Plans (DMP), a web-based low carbohydrate nutrition support service for people with T2DM. No study reviewed in this manuscript was associated with DMP.

\section{Multimedia Appendix 1}

Table 4. Intervention components, attrition, usability and modes and methods of delivery.

[PDF File (Adobe PDF File), 88 KB-Multimedia Appendix 1]

\section{Multimedia Appendix 2}

Table 5. Process evaluation measures.

[PDF File (Adobe PDF File), 66 KB-Multimedia Appendix 2]

\section{References}

1. Kaiser AB, Zhang N, Der Pluijm WV. Global Prevalence of Type 2 Diabetes over the Next Ten Years (2018-2028). Diabetes 2018 May;67(Supplement 1):202-LB. [doi: 10.2337/db18-202-lb]

2. American Diabetes Association. Standards of Medical Care in Diabetes 2019. Diabetes Care (Supplement 1). 2019. URL: https://care.diabetesjournals.org/content/diacare/suppl/2018/12/17/42.Supplement 1.DC1/DC 42 S1 2019 UPDATED. pdf [accessed 2019-07-15]

3. Stratton IM, Adler AI, Neil HA, Matthews DR, Manley SE, Cull CA, et al. Association of glycaemia with macrovascular and microvascular complications of type 2 diabetes (UKPDS 35): prospective observational study. BMJ 2000 Aug 12;321(7258):405-412 [FREE Full text] [doi: 10.1136/bmj.321.7258.405] [Medline: 10938048]

4. Evert AB, Dennison M, Gardner CD, Garvey WT, Lau KHK, MacLeod J, et al. Nutrition Therapy for Adults With Diabetes or Prediabetes: A Consensus Report. Diabetes Care 2019 May 18;42(5):731-754 [FREE Full text] [doi: 10.2337/dci19-0014] [Medline: $\underline{\text { 31000505] }}$

5. Lopez JMS, Katic BJ, Fitz-Randolph M, Jackson RA, Chow W, Mullins CD. Understanding preferences for type 2 diabetes mellitus self-management support through a patient-centered approach: a 2-phase mixed-methods study. BMC Endocr Disord 2016 Jul 18;16(1):41 [FREE Full text] [doi: 10.1186/s12902-016-0122-x] [Medline: 27430259]

6. Pal K, Dack C, Ross J, Michie S, May C, Stevenson F, et al. Digital Health Interventions for Adults With Type 2 Diabetes: Qualitative Study of Patient Perspectives on Diabetes Self-Management Education and Support. J Med Internet Res 2018 Jan 29;20(2):e40 [FREE Full text] [doi: 10.2196/jmir.8439] [Medline: 29463488]

7. Cassimatis M, Kavanagh DJ, Smith AC. Perceived Needs for Supported Self-management of Type 2 Diabetes: A Qualitative Investigation of the Potential for a Web-based Intervention. Australian Psychologist 2014 Mar 10;49(2):75-85. [doi: 10.1111/ap.12050]

8. Booth AO, Lowis C, Dean M, Hunter SJ, McKinley MC. Diet and physical activity in the self-management of type 2 diabetes: barriers and facilitators identified by patients and health professionals. Prim Health Care Res Dev 2013 Jul;14(3):293-306. [doi: 10.1017/S1463423612000412] [Medline: 23739524]

9. Kennedy M, Dunning T. Diabetes education: essential but underfunded in Australia. Diabetes \& Primary Care Australia 2017;2(1):e [FREE Full text]

10. Pereira K, Phillips B, Johnson C, Vorderstrasse A. Internet delivered diabetes self-management education: a review. Diabetes Technol Ther 2015 Jan;17(1):55-63. [doi: 10.1089/dia.2014.0155] [Medline: 25238257]

11. Managing diabetes: improving services for people with diabetes. Commission for Healthcare Audit Inspection, London, UK. URL: https://www.yearofcare.co.uk/sites/default/files/pdfs/Managing diabetes.pdf [accessed 2019-08-19]

12. Australian Diabetes Educators Association. Workforce in Diabetes Education (Online). URL: https://members.adea.com.au/ resources-2/workforce-in-diabetes-education/ [accessed 2020-08-19]

13. Chatterjee S, Davies MJ, Heller S, Speight J, Snoek FJ, Khunti K. Diabetes structured self-management education programmes: a narrative review and current innovations. Lancet Diabetes Endocrinol 2018 Dec;6(2):130-142. [doi: 10.1016/S2213-8587(17)30239-5] [Medline: 28970034]

14. Odgers-Jewell K, Isenring EA, Thomas R, Reidlinger DP. Group-based education for patients with type 2 diabetes: a survey of Australian dietitians. Aust J Prim Health 2017 Sep;23(4):364-372. [doi: 10.1071/PY16156] [Medline: 28566113]

15. Karekla M, Kasinopoulos O, Neto DD, Ebert DD, Van Daele T, Nordgreen T, et al. Best Practices and Recommendations for Digital Interventions to Improve Engagement and Adherence in Chronic Illness Sufferers. European Psychologist 2019 Jan;24(1):49-67. [doi: 10.1027/1016-9040/a000349]

16. Li J, Parrott S, Sweeting M, Farmer A, Ross J, Dack C, et al. Cost-Effectiveness of Facilitated Access to a Self-Management Website, Compared to Usual Care, for Patients With Type 2 Diabetes (HeLP-Diabetes): Randomized Controlled Trial. J Med Internet Res 2018 Jun 08;20(6):e201 [FREE Full text] [doi: 10.2196/jmir.9256] [Medline: 29884608] 
17. Ramadas A, Quek KF, Chan CKY, Oldenburg B. Web-based interventions for the management of type 2 diabetes mellitus: a systematic review of recent evidence. Int J Med Inform 2011 Jun;80(6):389-405. [doi: 10.1016/j.ijmedinf.2011.02.002] [Medline: 21481632]

18. Kitsiou S, Paré G, Jaana M, Gerber B. Effectiveness of mHealth interventions for patients with diabetes: An overview of systematic reviews. PLoS One 2017;12(3):e0173160 [FREE Full text] [doi: 10.1371/journal.pone.0173160] [Medline: 28249025]

19. Fu H, McMahon SK, Gross CR, Adam TJ, Wyman JF. Usability and clinical efficacy of diabetes mobile applications for adults with type 2 diabetes: A systematic review. Diabetes Res Clin Pract 2017 Sep;131:70-81. [doi: 10.1016/j.diabres.2017.06.016] [Medline: 28692830]

20. Nangrani N, Malabu U, Vangaveti V. Outcomes of Telehealth in the Management of Type 2 Diabetes-A Systematic Review and Meta-analysis of Randomised Controlled Trials. Diabetes 2018 May;67(Supplement 1):1298-P. [doi: 10.2337/db18-1298-p]

21. Kebede MM, Zeeb H, Peters M, Heise TL, Pischke CR. Effectiveness of Digital Interventions for Improving Glycemic Control in Persons with Poorly Controlled Type 2 Diabetes: A Systematic Review, Meta-analysis, and Meta-regression Analysis. Diabetes Technol Ther 2018 Nov;20(11):767-782. [doi: 10.1089/dia.2018.0216] [Medline: 30257102]

22. Cotterez AP, Durant N, Agne AA, Cherrington AL. Internet interventions to support lifestyle modification for diabetes management: a systematic review of the evidence. J Diabetes Complications 2014;28(2):243-251 [FREE Full text] [doi: 10.1016/j.jdiacomp.2013.07.003] [Medline: 24332469]

23. Moher D, Liberati A, Tetzlaff J, Altman DG. Preferred reporting items for systematic reviews and meta-analyses: the PRISMA statement. PLoS Med 2009 Jul 21;6(7):e1000097 [FREE Full text] [doi: 10.1371/journal.pmed.1000097] [Medline: 19621072]

24. Neve M, Morgan PJ, Jones PR, Collins CE. Effectiveness of web-based interventions in achieving weight loss and weight loss maintenance in overweight and obese adults: a systematic review with meta-analysis. Obes Rev 2010 Apr;11(4):306-321. [doi: 10.1111/j.1467-789X.2009.00646.x] [Medline: 19754633]

25. Pal K, Eastwood SV, Michie S, Farmer A, Barnard ML, Peacock R, et al. Computer-based interventions to improve self-management in adults with type 2 diabetes: a systematic review and meta-analysis. Diabetes Care 2014 Jun;37(6):1759-1766. [doi: 10.2337/dc13-1386] [Medline: 24855158]

26. Pal K, Eastwood SV, Michie S, Farmer AJ, Barnard ML, Peacock R, et al. Computer-based diabetes self-management interventions for adults with type 2 diabetes mellitus. Cochrane Database Syst Rev 2013;3:CD008776. [doi: 10.1002/14651858.CD008776.pub2] [Medline: 23543567]

27. Sterne JAC, Savović J, Page MJ, Elbers RG, Blencowe NS, Boutron I, et al. RoB 2: a revised tool for assessing risk of bias in randomised trials. BMJ 2019 Aug 28;366:14898. [doi: 10.1136/bmj.14898] [Medline: 31462531]

28. Hansel B, Giral P, Gambotti L, Lafourcade A, Peres G, Filipecki C, et al. A Fully Automated Web-Based Program Improves Lifestyle Habits and HbA1c in Patients With Type 2 Diabetes and Abdominal Obesity: Randomized Trial of Patient E-Coaching Nutritional Support (The ANODE Study). J Med Internet Res 2017 Nov 08;19(11):e360 [FREE Full text] [doi: 10.2196/jmir.7947] [Medline: 29117929]

29. Ramadas A, Chan CKY, Oldenburg B, Hussein Z, Quek KF. Randomised-controlled trial of a web-based dietary intervention for patients with type 2 diabetes: changes in health cognitions and glycemic control. BMC Public Health 2018 Dec 08;18(1):716 [FREE Full text] [doi: 10.1186/s12889-018-5640-1] [Medline: 29884161]

30. Saslow LR, Mason AE, Kim S, Goldman V, Ploutz-Snyder R, Bayandorian H, et al. An Online Intervention Comparing a Very Low-Carbohydrate Ketogenic Diet and Lifestyle Recommendations Versus a Plate Method Diet in Overweight Individuals With Type 2 Diabetes: A Randomized Controlled Trial. J Med Internet Res 2017 Feb 13;19(2):e36 [FREE Full text] [doi: 10.2196/jmir.5806] [Medline: 28193599]

31. Glasgow RE, Boles SM, McKay HG, Feil EG, Barrera M. The D-Net diabetes self-management program: long-term implementation, outcomes, and generalization results. Prev Med 2003 Apr;36(4):410-419. [doi:

10.1016/s0091-7435(02)00056-7] [Medline: 12649049]

32. Glasgow RE, Kurz D, King D, Dickman JM, Faber AJ, Halterman E, et al. Twelve-month outcomes of an Internet-based diabetes self-management support program. Patient Educ Couns 2012 Apr;87(1):81-92 [FREE Full text] [doi: 10.1016/j.pec.2011.07.024] [Medline: 21924576]

33. Ramadas A, Chan CKY, Oldenburg B, Hussien Z, Quek KF. A web-based dietary intervention for people with type 2 diabetes: development, implementation, and evaluation. Int J Behav Med 2015 Jun;22(3):365-373 [FREE Full text] [doi: 10.1007/s12529-014-9445-z] [Medline: 25274015]

34. Glasgow RE, Strycker LA, Kurz D, Faber A, Bell H, Dickman JM, et al. Recruitment for an internet-based diabetes self-management program: scientific and ethical implications. Ann Behav Med 2010 Aug;40(1):40-48. [doi: 10.1007/s12160-010-9189-1] [Medline: 20411443]

35. Glasgow RE, Christiansen SM, Kurz D, King DK, Woolley T, Faber AJ, et al. Engagement in a diabetes self-management website: usage patterns and generalizability of program use. J Med Internet Res 2011;13(1):e9 [FREE Full text] [doi: 10.2196/jmir.1391] [Medline: 21371992] 
36. Ramadas A, Quek KF, Chan CKY, Oldenburg B, Hussein Z. Randomised-controlled trial of a web-based dietary intervention for patients with type 2 diabetes mellitus: study protocol of myDIDeA. BMC Public Health 2011 May 21;11:359 [FREE Full text] [doi: 10.1186/1471-2458-11-359] [Medline: 21599990]

37. McKay HG, Glasgow RE, Feil EG, Boles SM, Barrera MJ. Internet-based diabetes self-management and support: Initial outcomes from the Diabetes Network project. Rehabilitation Psychology 2002;47(1):31-48. [doi: 10.1037/0090-5550.47.1.31]

38. Lie SS, Karlsen B, Oord ER, Graue M, Oftedal B. Dropout From an eHealth Intervention for Adults With Type 2 Diabetes: A Qualitative Study. J Med Internet Res 2017 May 30;19(5):e187 [FREE Full text] [doi: 10.2196/jmir.7479] [Medline: 28559223]

39. Medical Research Council. Developing and evaluating complex interventions: Following considerable development in the field since 2006, MRC and NIHR have jointly commissioned an update of this guidance to be published in 2019 (Online). URL: https://mrc.ukri.org/documents/pdf/complex-interventions-guidance/ [accessed 2020-08-29]

40. LeRouge $\mathrm{C}$, Wickramasinghe $\mathrm{N}$. A review of user-centered design for diabetes-related consumer health informatics technologies. J Diabetes Sci Technol 2013 Jul 01;7(4):1039-1056 [FREE Full text] [doi: 10.1177/193229681300700429] [Medline: 23911188]

41. Murray E, Sweeting M, Dack C, Pal K, Modrow K, Hudda M, et al. Web-based self-management support for people with type 2 diabetes (HeLP-Diabetes): randomised controlled trial in English primary care. BMJ Open 2017 Sep 27;7(9):e016009 [FREE Full text] [doi: 10.1136/bmjopen-2017-016009] [Medline: 28954789]

42. Yu CH, Parsons JA, Hall S, Newton D, Jovicic A, Lottridge D, et al. User-centered design of a web-based self-management site for individuals with type 2 diabetes - providing a sense of control and community. BMC Med Inform Decis Mak 2014;14:60 [FREE Full text] [doi: 10.1186/1472-6947-14-60] [Medline: 25056379]

43. Cradock KA, ÓLaighin G, Finucane FM, McKay R, Quinlan LR, Martin GKA, et al. Diet Behavior Change Techniques in Type 2 Diabetes: A Systematic Review and Meta-analysis. Diabetes Care 2017 Dec;40(12):1800-1810. [doi: 10.2337/dc17-0462] [Medline: 29162585]

44. Huntriss R, Campbell M, Bedwell C. The interpretation and effect of a low-carbohydrate diet in the management of type 2 diabetes: a systematic review and meta-analysis of randomised controlled trials. Eur J Clin Nutr 2018 Mar;72(3):311-325. [doi: 10.1038/s41430-017-0019-4] [Medline: 29269890]

45. McArdle PD, Greenfield SM, Rilstone SK, Narendran P, Haque MS, Gill PS. Carbohydrate restriction for glycaemic control in Type 2 diabetes: a systematic review and meta-analysis. Diabet Med 2019 Mar;36(3):335-348. [doi: 10.1111/dme.13862] [Medline: $\underline{30426553}$ ]

\section{Abbreviations}

ADA: American Diabetes Association

ANODE: Accompagnement Nutritionnel de l'Obésité et du Diabète par Ecoaching

CASM/+: computer-assisted self-management/computer-assisted self-management plus social support

CINAHL: Cumulative Index of Nursing and Allied Health Literature

CVD: cardiovascular disease

DKAB: Dietary Knowledge, Attitude and Behavior

D-Net: Diabetes Network

$\mathbf{H b A}_{1 \mathbf{c}}$ : hemoglobin $\mathrm{A}_{1 \mathrm{c}}$

mHealth: mobile health

myDIDeA: Malaysian Dietary Intervention for People with Type 2 Diabetes: An e-Approach

NCI: National Cancer Institute

PRISMA: Preferred Reporting Items for Systematic Reviews and Meta-Analyses

PROSPERO: International Prospective Register of Systematic Reviews

RCT: randomized controlled trial

RoB 2: Cochrane risk-of-bias tool for randomized trials

T2DM: type 2 diabetes mellitus

VLCKD: very low carbohydrate ketogenic diet 
Edited by G Eysenbach; submitted 29.09.19; peer-reviewed by K Johnson, $R$ Meseri; comments to author 19.05.20; revised version received 30.05.20; accepted 03.06.20; published 28.08 .20

Please cite as:

Dening J, Islam SMS, George E, Maddison R

Web-Based Interventions for Dietary Behavior in Adults With Type 2 Diabetes: Systematic Review of Randomized Controlled Trials $J$ Med Internet Res 2020;22(8):e16437

URL: http://www.jmir.org/2020/8/e16437/

doi: $10.2196 / 16437$

PMID: $\underline{32857059}$

CJedha Dening, Sheikh Mohammed Shariful Islam, Elena George, Ralph Maddison. Originally published in the Journal of Medical Internet Research (http://www.jmir.org), 28.08.2020. This is an open-access article distributed under the terms of the Creative Commons Attribution License (https://creativecommons.org/licenses/by/4.0/), which permits unrestricted use, distribution, and reproduction in any medium, provided the original work, first published in the Journal of Medical Internet Research, is properly cited. The complete bibliographic information, a link to the original publication on http://www.jmir.org/, as well as this copyright and license information must be included. 